\title{
Como satisfazer nossas necessidades de interagir online em diferentes níveis de intimidade? Um estudo sobre a comunicação nas comunidades virtuais
}

\author{
Mariana Santiago de Matos-Silva ${ }^{*}$, , Rosane de Albuquerque dos Santos Abreu ${ }^{a, b}, \&$ \\ Ana Maria Nicolaci-da-Costa ${ }^{a}$ \\ ${ }^{a}$ Pontifícia Universidade Católica do Rio de Janeiro, Rio de Janeiro, Brasil \& \\ ${ }^{\mathrm{b}}$ Fundação Oswaldo Cruz/Farmanguinhos, Rio de Janeiro, Brasil
}

\begin{abstract}
RESUMO
O presente estudo teve como objetivo investigar o uso que vem sendo feito das chamadas comunidades virtuais. Entrevistamos membros de algumas comunidades e constatamos que, nelas, muitas vezes desconhecidos se aproximavam e iniciavam uma relação de amizade. Os ambientes das comunidades investigadas, contudo, não ofereciam recursos para o aprofundamento dessas relações, pois não disponibilizavam espaços ou recursos que permitissem a interação de poucas pessoas ou até mesmo de apenas duas. Por esse motivo, quando desejavam se aproximar mais intimamente de outros membros, os participantes dessas comunidades virtuais recorriam a ambientes complementares, tais como o MSN e o Skype.
\end{abstract}

Palavras-chave: comunidades virtuais; redes sociais; internet; intimidade.

\section{ABSTRACT \\ How to satisfy our needs to interact online at different levels of intimacy? A study of communication in virtual communities}

This study aimed at investigating the current use of the so-called virtual communities. Members of some communities were interviewed. It became clear that, in these communities, it often happened that strangers met people with whom they wanted to be friends. The environments of the communities investigated, however, did not offer means for deepening these relationships, because they did not make available spaces or tools that would allow few or even just two people to interact intimately. For this reason, when they wanted to get closer to other members, the participants of these virtual communities turned to complementary environments such as MSN and Skype.

Keywords: virtual communities; social networks; internet; intimacy.

Por mais diferentes que as sociedades possam ser, sua existência é prova de que formar grupos é uma necessidade da espécie humana. Para Trotter (1919/ 1953), essa necessidade é como um "instinto gregário", tão inato no ser humano como os instintos de autopreservação, nutrição e reprodução. Já Simmel (1910/1949) afirma que o que leva as pessoas a se unirem é um "impulso para a sociabilidade". De acordo com sua visão, este impulso faz com que a principal motivação para a agregação resida na satisfação obtida a partir do simples fato de alguém se sentir associado a outras pessoas.
Um dos tipos de grupos que surgem em consequência do "instinto gregário" ou do "impulso para a sociabilidade" são as comunidades. De acordo com Nisbet (1973), o termo comunidade "abrange todas as formas de relacionamento caracterizadas por um grau elevado de intimidade pessoal, profundeza emocional, engajamento moral, coerção social e continuidade no tempo" (Nisbet, 1973, p. 255). Na era pré-industrial, as comunidades feudais eram os pilares dos relacionamentos sociais (Nisbet, 1973). Então, as comunidades eram frequentemente fechadas, dado que eram constituídas por pessoas que pertenciam a uma mesma família, habitavam um mesmo local e/ou compartilhavam as mesmas crenças (Nisbet, 1966). A Revolução

\footnotetext{
Endereço para correspondência: Mariana Santiago de Matos-Silva - marianasantiagodematos@gmail.com
} 
Industrial veio mudar tudo isso ao gerar uma ruptura radical com a organização social feudal e instaurar uma nova ordem. Foram vários os autores que, sendo testemunhas oculares dessa transformação, se dedicaram à análise das principais características da nova realidade social (com maior ou menor grau de saudosismo em relação àquilo que havia sido extinto). Entre eles, destacaremos Ferdinand de Tönnies (1887/1978), Émile Durkheim (1897/1982) e Georg Simmel (1910/ 1949).

Tönnies (1887/1978), por exemplo, estabelece um contraste entre comunidade (Gemeinshaft) e sociedade (Gesellshaft) para dar conta do funcionamento social nas eras pré e pós-industrial, respectivamente. Sem entrarmos em detalhes para não nos alongarmos em uma discussão que foge ao escopo deste artigo (ver Nicolaci-da-Costa, 1997), as análises de Tönnies, complementadas pelas de Durkheim (1897/1982) e Simmel (1910/1949), entre outros, mostram como o sistema feudal de base predominantemente comunitária deu lugar ao sistema capitalista, no qual passaram a imperar o individualismo, a racionalidade e o cálculo.

A fragmentação do todo social comunitário, associada à migração da mão-de-obra rural para as sedes das primeiras indústrias, fez com que o indivíduo fosse projetado para o desconhecido, para a vida entre estranhos nas grandes metrópoles, para a solidão (Durkheim, 1897/1982; Simmel, 1910/1949). Desapareceram aqueles que eram vistos como "os grilhões da tradição" e, com eles, a segurança e a garantia de uma vida em que cada um se sentia - e de fato era - um membro de uma rede de relações afetivas entre homens totais que o apoiavam ao longo de sua vida. $\mathrm{O}$ novo sistema substituiu os fortes vínculos afetivos entre homens totais por vínculos contratuais, racionais, cronometrados e baseados em interesses pontuais centrados no indivíduo. Embora isso não tenha impedido que o instinto gregário sobrevivesse (as agregações sociais simplesmente mudaram de forma), ao longo do século XX o comunitarismo, pelo menos tal como havia existido antes, parecia ter desaparecido.

A chegada da Internet gerou mudanças radicais nesse quadro. Isso porque, desde os primeiros momentos de sua difusão para o grande público, tornouse óbvia para seus usuários a sua vocação para conectar pessoas espalhadas ao redor do mundo do mesmo modo que conectava os computadores mundiais.

\section{AS COMUNIDADES VIRTUAIS}

Na virada do século XX para o XXI, a difusão da Internet fez surgir uma nova plataforma de vida - a virtual - que abriu uma gama de novas possibilidades de relacionamentos interpessoais (Nicolaci-da-Costa, 2006). Nos primórdios dessa nova era, as pessoas interagiam principalmente através de e-mails ou de chats (IRC ou webchats). Um pouco mais tarde, contudo, surgiram muitos outros ambientes e ferramentas para o estabelecimento e/ou manutenção das relações entre desconhecidos e/ou conhecidos. Entre eles estavam programas como o ICQ e o MSN Messenger, site de paquera, blogs, jogos online e, mais recentemente, as redes sociais. Todos esses recursos, amplamente adotados pelo público em geral, fizeram com que o comunitarismo ressurgisse, porém com uma nova roupagem.

Esse novo comunitarismo foi analisado por Rheingold (1993), um dos primeiros a utilizarem a expressão "comunidade virtual". Ele define estas comunidades como "agregações sociais que emergem da Rede quando há um número suficiente de pessoas que se mantêm em discussões suficientemente longas, com suficientes emoções, formando redes de relações pessoais em ambientes virtuais" (Rheingold, 1993). Rheingold percebe a Internet como um terreno bastante fértil para a formação de comunidades. Chega a pensar que a comunicação mediada por computadores inevitavelmente gera comunidades virtuais, da mesma maneira como micro-organismos inevitavelmente formam colônias.

Castells (2003), outro estudioso da contemporaneidade, afirma que a Internet está permitindo um retorno àquele que denomina "comunitarismo renovado". Para ele, uma das razões por trás desse ressurgimento do comunitarismo na Internet é o fato de o ambiente virtual albergar qualquer tipo de ideia, pensamento, ideologia, crença etc. Ainda segundo Castells, independentemente do motivo que possa agregar seus membros, as comunidades online possuem duas características fundamentais em comum. Uma delas é a possibilidade de expressão livre e horizontal, sem uma entidade censora institucional, governamental ou da mídia. A outra é o fato de qualquer pessoa poder encontrar seu lugar na Internet e, se não o encontrar, poder criá-lo e divulgá-lo, dando início a uma nova comunidade ou rede de relacionamentos.

Assim como Rheingold e Castells, Maffesoli (2006) também pensa que, com o advento da Internet, emergiu um novo comunitarismo, percebido como um "retorno ao tribalismo". Para ele, o tecido social de hoje é constituído por diversas "tribos", reunidas em torno de "totens", que podem ser, por exemplo, gostos sexuais, relações de amizade ou preferências religiosas. Nessas "tribos", o compartilhamento de afetos, sentimentos e emoções é fundamental. Na pós-moder- 
nidade, tais "tribos" podem emergir tanto a partir do território do "real" como do virtual. Onde quer que estas tribos se encontrem, sua característica principal é a de que o desejo do grupo é mais importante do que anseios individuais.

\section{ALGUMAS CARACTERÍSTICAS DAS COMUNIDADES VIRTUAIS}

Para Rheingold, a despeito da ausência do contato face a face, as comunidades virtuais levam seus membros a estabelecerem vínculos entre si. Isso porque, em suas próprias palavras:

[...] pessoas em comunidades virtuais fazem quase tudo o que as pessoas fazem na vida real, mas nós deixamos nossos corpos de fora. Você não pode beijar ninguém e ninguém pode socá-lo no nariz, mas muito pode acontecer dentro dos seus limites. (Rheingold, 1993)

Castells afirma que "as redes online [...] podem formar comunidades, comunidades virtuais, diferentes das físicas, mas não necessariamente menos intensas ou menos eficazes na criação de laços e na mobilização" (Castells, 2003, p. 109). Marcelo (2004) concorda com a ideia de Castells, e considera que comunidades virtuais e tradicionais possuem uma mesma característica fundamental: o desenvolvimento do sentimento de pertença entre os elementos que as compõem. A seu ver, este sentimento é uma das características mais importantes, senão a mais importante, dessas comunidades (Marcelo, 2004). Para ela, o fato de a interação se dar em um ambiente virtual não faz com que as relações que emergem sejam menos reais do que aquelas que brotam em ambientes "físicos", já que os envolvidos são "pessoas reais, que estabelecem relações reais" (Marcelo, 2004, p. 275).

Se, por um lado, comunidades virtuais se assemelham às tradicionais pelo tipo de envolvimento que surge entre seus membros, há, por outro, diferenças marcantes. A principal delas é o fato de a formação comunidades online ser aberta. Na era pré-industrial, como já foi visto, as comunidades eram quase sempre "fechadas" (delas participando aqueles que eram membros de uma família, de uma vizinhança e/ou de uma seita religiosa). A filiação às comunidades virtuais do século XXI, por sua vez, está diretamente associada ao modelo capitalista surgido a partir da Revolução Industrial, que gerou relações sociais centradas no indivíduo. Isso porque a participação em comunidades virtuais é quase sempre determinada por inte- resses, valores, afinidades e projetos de cada pessoa (Castells, 2003; Corrêa, 2004; Marcelo, 2004). Tal tipo de filiação resulta no que Wellman (2001) chama de "comunidades personalizadas" e que Castells (2003) denomina "individualismo em rede". Para este último autor, o "individualismo em rede" seria um novo padrão de sociabilidade, para o qual a Internet através das comunidades virtuais, principalmente serve como suporte.

Wellman e Gulia (1997), entretanto, chamam a atenção para o fato de que nem todo agrupamento que surge na Internet pode ser classificado como uma comunidade virtual. Para eles, as comunidades são caracterizadas pelo estabelecimento de relações sociais fortes, nas quais seus membros encontram informações, companhia, apoio e a sensação de pertencimento. Lemos (2002) compartilha essa ideia, considerando que o que define a existência de uma comunidade é o envolvimento entre seus membros e a permanência temporal. Assim, um mesmo ambiente da Web pode ser usado tanto de maneira comunitária como não comunitária. Quando o ambiente é usado de modo comunitário, há um sentimento de afinidade que leva ao compartilhamento de emoções e à troca de experiências pessoais, fundamentais para a coesão do grupo. Se o ambiente não é usado de maneira comunitária, ele pode ser considerado apenas uma "agregação eletrônica onde os participantes não se sentem envolvidos, sendo apenas um lócus de encontro e de compartilhamento de informações e experiências de caráter totalmente efêmero e desterritorializado" (Lemos, 2002, online).

Nos últimos anos, o uso de comunidades online cresceu a olhos vistos. Esse crescimento se deu principalmente a partir do início da Web colaborativa, quando os usuários deixaram de ser meros espectadores para se tornarem também participantes ativos (Di Luccio, 2010). A possibilidade de publicar textos, fotos, vídeos e outros tipos de conteúdo, gerou ambientes que favorecem a união de pessoas. Entre estes ambientes, estão as redes sociais, que permitem que o usuário crie sua própria rede de relacionamentos e participe de comunidades virtuais, havendo espaços específicos destinados a estas últimas. Acontece, no entanto, que vem sendo observada recentemente a existência, na Rede, de outros ambientes - não projetados originalmente para hospedarem comunidades que são espontaneamente utilizados de modo comunitário por seus frequentadores. Um bom exemplo são os blogs estudados por Di Luccio e Nicolaci-da-Costa (2007). A pesquisa feita por essas autoras revelou que 
estes blogs - que inicialmente tinham o objetivo de serem "diários pessoais" - haviam se tornado espaços comunitários em que blogueiros criavam e mantinham diferentes tipos de laço social.

A formação de comunidades virtuais em ambientes não desenvolvidos com este fim, por sua vez, ilustra bem a posição de Castells de que "as pessoas, as instituições, as companhias e a sociedade em geral transformam a tecnologia, qualquer tecnologia, apropriando-a, modificando-a, experimentando-a" (Castells, 2003, p. 10). Foi exatamente essa proliferação de diferentes tipos de comunidade na Web, aliada ao uso comunitário de ambientes não projetados com esta finalidade, que motivou a presente pesquisa, cujos detalhes descrevemos a seguir.

\section{A Pesquisa}

A proliferação de comunidades virtuais e a observação de que diversos ambientes/recursos da Internet estavam sendo utilizados de modo comunitário suscitaram diversos questionamentos. Entre eles se destacavam os seguintes. De que modo estão sendo usadas as comunidades projetadas como tal e aquelas que emergem espontaneamente? Com que finalidades seus membros a elas se filiam? Serão elas realmente "comunidades", ou apenas agregações de pessoas? Geram elas o sentimento de pertença? Como acontecem o compartilhamento de emoções e a troca de experiências pessoais que dão lugar a esse sentimento de pertença? Nosso estudo teve, portanto, como objetivo obter respostas para essas perguntas.

\section{MÉTODO}

\section{Seleção dos Entrevistados}

Os entrevistados foram selecionados a partir de um único critério: serem participantes ativos de pelo menos uma comunidade virtual. Tal opção foi feita por desejarmos pesquisar o uso de comunidades em geral. Restrições quanto a gênero, idade ou uso de determinado tipo de comunidade poderia nos levar a resultados desnecessariamente limitados tendo em vista que queríamos investigar o uso de comunidades diversas, situadas em ambientes variados (site de redes sociais, blogs, jogos, chats, etc.). O recrutamento dos entrevistados foi feito tanto a partir da indicação de amigos e conhecidos como através de contato online, estabelecido nas próprias comunidades.

\section{Perfil dos Entrevistados}

Entrevistamos 13 pessoas, 7 mulheres e 6 homens, cujas idades variavam entre 16 e 63 anos. A maioria era participante de pelo menos uma comunidade virtual há um período entre 1 e 4 anos.

As comunidades das quais os entrevistados participavam se situavam, em sua maioria, no Orkut que, à época da pesquisa, era a rede social mais acessada pelo público brasileiro. Neste ambiente, as comunidades eram as seguintes:

- "Noivas do Rio de Janeiro". Nesta, as participantes trocam informações sobre os preparativos para seus casamentos. Duas entrevistadas faziam parte desta comunidade.

- "Bulimia e Anorexia: eu superei”. Comunidade na qual pessoas que sofrem destas doenças trocam, entre outras, informações sobre suas consequências e dicas para se manterem magras. Entrevistamos uma jovem que pertencia a esta comunidade.

- "Studio Paragem". Pertence a um estúdio de fotografia e visa à captação e aproximação de clientes, sendo um espaço para a troca de experiências, elogios, críticas e esclarecimento de dúvidas. Entrevistamos o administrador desta comunidade.

- Comunidades em homenagem às cantoras Adriana Calcanhotto e Maria Bethânia. Entrevistamos uma jovem que fazia parte destas comunidades.

- Comunidade "Chuck - Serie", sobre o seriado de televisão "Chuck". Uma entrevistada fazia parte desta comunidade.

- "Filosofia para não-filósofos", "Magia do Caos!", "Discografias - a ressurreição", "Cálculo? Integrei pra Deus" e "Aleister Crowley". Entrevistamos um rapaz que era membro destas comunidades, nas quais assuntos diversos são discutidos.

- "Revolucionários de Sofá", "Eu amo a Björk", "Vegetarianos". Um entrevistado era membro destas comunidades.

Outros entrevistados pertenciam a comunidades fora do Orkut, tais como:

- Comunidade do jogo Ragnarok, que é um RPG multiusuário jogado online. No jogo, formamse equipes (os "clãs") e há espaços que abrigam tanto fóruns de discussão dos quais participam jogadores em geral como fóruns específicos para os membros de cada "clã". Dois entrevistados eram membros desta comunidade. 
- Comunidade sobre autismo no Yahoo! Grupos, na qual familiares de autistas trocam informações sobre a doença e compartilham experiências. Uma entrevistada pertencia a esta comunidade.

- Comunidade do site "Lance! Activo", um site de esportes destinado à discussão entre leitores. Um entrevistado pertencia a este grupo.

- Comunidade de troca de e-mails religiosos com pessoas que pertencem a uma mesma paróquia. Uma entrevistada fazia parte desta comunidade.

\section{COLETA DE DADOS}

Os dados foram coletados por meio de 13 entrevistas individuais realizadas on-line (Nicolaci-da-Costa, Romão-Dias, \& Di Luccio, 2009). As entrevistas foram realizadas com base em um roteiro construído de acordo com as diretrizes do Método de Explicitação do Discurso Subjacente, o MEDS (Nicolaci-da-Costa, 2007). Este método tem como objetivo tornar visíveis conteúdos que vão além do discurso racional dos entrevistados, fazendo emergir aspectos psicológicos dos quais eles nem sempre têm consciência. Tais aspectos são importantes, pois eles revelam concepções, ideias e valores vigentes no contexto social no qual o participante está inserido. O MEDS não visa, portanto, verificar hipóteses (como outros métodos), mas conhecer opiniões, crenças, experiências e sentimentos dos entrevistados. Assim sendo, o roteiro era constituído por itens que serviam de lembretes para que os entrevistadores formulassem perguntas abertas (que não sugerem nenhuma resposta) sobre os tópicos a que diziam respeito durante as próprias entrevistas (a leitura de perguntas previamente construídas soa artificial e prejudica o clima de naturalidade que se deseja que a entrevista tenha). A ordem de tais itens podia ser alterada de modo que fosse possível seguir o fluxo do raciocínio dos entrevistados, o que tornava a entrevista semelhante a uma conversa informal, agradável para o entrevistado. Dado que uma conversa jamais é composta somente por perguntas abertas, ao longo das entrevistas, eram incluídos alguns itens destinados a gerar perguntas fechadas (cujas respostas são 'sim' e 'não'), complementados por perguntas como "por quê?", "como?", "você pode me explicar um pouco mais?" e semelhantes. A qualquer momento, o entrevistador podia fazer perguntas de aprofundamento (Por quê? Como? Dá para explicar melhor?) para que o entrevistado fornecesse maiores detalhes sobre $\mathrm{o}$ que estava falando.
Os itens que faziam parte do roteiro de entrevistas eram bastante concisos e resumidos, já que eles tinham apenas a função de serem lembretes para os entrevistadores. Para que o leitor compreenda bem do que se tratavam tais itens, eles serão apresentados a seguir de forma mais extensa do que aquela que os entrevistadores (que já tinham familiaridade com o roteiro) usavam como guia. Os referidos itens foram agrupados nos seguintes blocos temáticos:

Identificação: Nome que usa na(s) comunidade(s); idade; nível de escolaridade; profissão; estado civil; há quanto tempo usa a Rede; frequência com que se conecta; tempo diário que fica na Internet; o que costuma fazer na Internet; há quanto tempo participa da comunidade; participação em outras comunidades; conhecimento de outras comunidades; conceito de comunidade; o que é necessário em uma comunidade virtual.

A comunidade que mais frequenta: Como conheceu a comunidade; como entrou na comunidade; por que entrou; como foi a adaptação à comunidade; o que fez continuar na comunidade; como participa; tempo que disponibiliza para participar da comunidade; expectativas sobre a comunidade; se houve mudanças pessoais decorrentes da participação na comunidade, em caso positivo, quais?; se o/a entrevistado se sente pertencendo à comunidade (por quê?), em caso positivo, quando começou a se sentir assim (por quê?); mobilidade da comunidade para outros ambientes (online e offline), diferenças entre os ambientes; se a comunidade virtual tem congênere no real, em caso positivo, qual?; como caracterizaria esta comunidade.

As relações na comunidade: a interação entre os membros; tipo de relacionamento; estabelecimento de laços com outros participantes; reação à chegada e saída de membros; em que situações escreve e por quê; como reage quando não tem resposta; se conhece pessoalmente algum membro (como foi esse processo?); como foi o encontro presencial (quando houve); comparação entre a relação na Internet e fora dela.

Todas as entrevistas foram feitas online, a partir do programa MSN Live Messenger, amplamente usado na época. A escolha deste meio se deu principalmente devido à familiaridade que os entrevistados tinham com este ambiente, requisito fundamental do MEDS (ver Nicolaci-da-Costa, Romão-Dias \& Di Luccio, 2009). Por ser o MSN um ambiente percebido como natural para os entrevistados, eles estariam à vontade para discorrer livremente sobre o que tínhamos a lhes perguntar. 


\section{Análise das Entrevistas}

Ainda seguindo as diretrizes do MEDS (Nicolacida-Costa, 2007), as entrevistas foram submetidas a uma análise feita em duas etapas. Na primeira delas, chamada de "interparticipantes", as respostas do grupo como um todo foram analisadas. Para isso, as respostas que todos participantes deram a cada uma das perguntas foram comparadas entre si, em busca de pontos em comum, ou recorrências. Uma vez identificadas, essas recorrências geraram categorias de análise iniciais, nas quais as respostas foram agrupadas.

Passamos, então, à segunda etapa, a análise "intraparticipantes". Nesta, analisamos individualmente o discurso de cada entrevistado em busca de inconsistências, incoerências e contradições. Quando essas inconsistências e/ou contradições eram encontradas no discurso de um participante, elas geravam novas categorias de análise que nos remetiam de volta à análise "interparticipantes". O objetivo desse retorno era o de verificar se uma ou outra inconsistência, incoerência ou contradição era uma peculiaridade do discurso de um ou outro participante específico ou se estava presente nos depoimentos dos demais entrevistados. Essa alternância entre os dois tipos de análise foi feita tantas vezes quanto necessárias, até que considerássemos que havíamos apreendido as nuanças de significado do material discursivo que havíamos coletado.

\section{RESULTADOS}

A apresentação dos resultados obtidos terá início com a análise dos motivos que levaram nossos entrevistados a se tornarem membros de uma ou outra comunidade. Antes, contudo, é importante assinalar que, como foi dito aos entrevistados, seus nomes/apelidos foram substituídos por outros, visando preservar suas identidades. Já seus discursos foram mantidos inalterados, tendo sido conservados eventuais erros ortográficos, de concordância, abreviações, gírias etc.

\section{Interesses Pessoais Motivam a Entrada nas Comunidades}

A maioria dos entrevistados escolheu uma ou outra comunidade e nela entrou por iniciativa própria, ou seja, sem o convite de ninguém. Em todos os casos, o tema tratado na comunidade escolhida era algo que, por razões diversas, despertava o interesse dos participantes na época de sua entrada. A maior parte das vezes, o ingresso se deveu à busca informações.

Duas participantes, por exemplo, entraram na comunidade de noivas para obter informações de forne- cedores de artigos de casamento. Foi o que explicitou Estela: "O motivo foi buscar referências de fornecedores / Saber de boas e más experiências etc.".

Em dois casos, as informações buscadas nas comunidades eram sobre assuntos que causavam ansiedade aos participantes. Ísis, que sofria de bulimia, passou a acessar uma comunidade sobre o tema para ter mais informações sobre a doença: "Qnd [quando] eu comecei a ter bulimia pesquisei no orkut para saber as consequências da doença".

Já Cláudia explicou que buscou uma comunidade sobre autismo assim que seu filho teve este diagnóstico. Eis o seu depoimento: "O meu mundo caiu. Não tinha mais vontade de nada só de procurar desesperadamente alguma coisa pra me falar que era apenas um engano, sei lá, desespero mesmo [...] Pesquisando, fui atrás".

Nem todos, no entanto, entraram em comunidades por estarem vivendo situações aflitivas. Alguns pesquisados decidiram fazer parte de grupos por lazer. Dois deles escolheram, para isso, a comunidade do jogo Ragnarok. Eduardo revelou suas razões: "como todo rpg [role playing game] online, mta [muita] gente, dinamico, divertido... um bom passa tempo".

Também por lazer Paulinho escolheu participar da comunidade de esportes "Lance Activo", onde disse ter encontrado uma oportunidade de relaxar: "Sempre participei de site politicos, assuntos complicados, sérios demais... então resolvi relaxar um pouco, fazer aquilo que gosto também...”.

A religião motivou o surgimento de uma comunidade da qual outra entrevistada fazia parte. Sabrina explicou que ela surgiu espontaneamente, a partir de e-mails religiosos enviados a diferentes amigos: " $O$ PCA [comunidade religiosa] surgiu meio sem querer / eu todos os dias lia a liturgia diária e dependendo do dia e da mensagem eu repassava aos amigos / só q foi crescendo / e qdo eu nao colocava o povo cobrava / aí combinamos em passar todos os dias [...] foi uma coisa onde todos entraram num acordo / e combinamos de passar todos os dias / nem sempre sou eu quem passa primeiro".

\section{Formam-se Laços Afetivos}

Embora nenhum dos entrevistados tenha entrado nas comunidades com o objetivo de buscar amigos, todos eles disseram que a participação no grupo surpreendentemente acabou gerando amizades. Para as duas noivas, as amizades vieram principalmente a partir do compartilhamento de expectativas e angús- 
tias em relação aos preparativos de seus casamentos. Sobre isso, Estela disse: " a princípio as noivas entram por causa disso [buscar informações de fornecedores] I mas a comunidade acba [acaba] funcionando como um desabafo dos estresses dos preparativos, das frustrações e realizações que vão acontecendo até o casamento e depois dele as noivas acabam se apegando e muitas delas (a maioria) continua acessando a comunidade depois de casadas".

Nayara, que fazia parte das comunidades que homenageiam cantoras, afirmou que fez ao menos quatro amizades, sendo que duas se tornaram relacionamentos amorosos: "já me aproximei de algumas pessoas, uma delas é uma amiga muito próxima hoje em dia [...] / [dessas, se tornaram] próximas a mim acho que umas 4 [pessoas] [...] duas vezes deu em namoro / umas outras duas uma grande amizade".

Para Eduardo, jogador de Ragnarok, a comunidade a que pertencia gerou laços fortes, que independiam de encontros presenciais: "meus melhores amigos HOJE eu conheci no jogo, e a maioria eu nunca vi pessoalmente [...] nao só sinto como existe esse laço. tanto do meu lado qnt do lado deles".

Kazuya, que também fazia parte da comunidade do jogo, mostrou partilhar a opinião de Eduardo: "esses clan [clãs] são compostos / por membros / que se identificam uns com os outros e acabam criando uma amizade [...] é bem comum uma pessoa que conhece online / ser um grande amigo seu sem se encontrar pessoalmente".

A sensação de estabelecer laços aconteceu mesmo quando o membro da comunidade não costumava escrever mensagens. Foi o que disse Cláudia, que frequentava em silêncio a comunidade sobre autismo: "Não sou de me manifestar, mas leio tudo que posso. Choro, sofro junto com eles, mais [mas] tudo em silêncio. Acaba criando essa cumplicidade pelas situações vividas".

Ísis, membro do grupo sobre bulimia, também participava sem escrever, apenas observava. Mesmo assim, ela revelou perceber que "as pessoas acabam se tornando amigas de verdade".

\section{Surgem Novos Assuntos}

Conforme os entrevistados formavam laços de amizade, o assunto principal das conversas passava a variar, quase sempre se distanciando do tema original que os havia levado a participarem da comunidade em questão. Sabrina, por exemplo, afirmou que, embora o assunto de seu grupo fosse a religião, outros temas interessantes também tinham espaço: "agora até eleiçao / se o assunto interessar o povo compartilha / não tem restriçao".

O mesmo aconteceu na comunidade de noivas, na qual o surgimento de amizades levou as integrantes a compartilharem também outros assuntos. De acordo com Estela: " $O$ assunto sempre começa em casamento mas lá de fala sobre tudo [...] tem uma que já casou a [há] mais de um ano [...] ela descobriu que tinha cancer pouquinho tempo antes de casar / e sempre mandava noticias no tópico das crônicas dela".

Eduardo disse que, com os amigos que fez a partir da comunidade do jogo Ragnarok, conversava sobre assuntos diversos. Eles eram, inclusive, fonte de apoio em momentos delicados: "[...] falamos de futebol, cinema, mulher, etc. [...] tipo amizade de boteco mesmo. dividir alegrias, tristezas. por mais que estejam longe dá pra contar com apoio deles".

Para Cristiano, que pertencia a diversas comunidades, os laços mais fortes surgem a partir de assuntos que fogem ao tema central do grupo. Ele disse que, em algumas situações, chegava a contar mais com amigos que fez nesses grupos do que com pessoas que conhece em sua vida offline: "Pois muitos temas seria difícil tratar com alguem conhecido, jah a internet possibilita eu encontrar pessoas com as mesmas dúvidas que eu e achar alguem para resolve-las".

\section{Diversificam-se os Ambientes}

Além da diversificação de assuntos, os pesquisados revelaram que os laços gerados a partir de sua participação nas comunidades fizeram com que passassem a se comunicar também por outros meios, a exemplo do MSN, Skype e blogs. Nayara deixou isso claro: “já conheci várias pessoas no orkut / [...] umas se tornaram mto próximas / e essas eu converso por msn, skype / as outras não".

Estela relatou que, a partir da comunidade de noivas, surgiu um grupo de troca de e-mails, pelo Yahoo!Grupos. Neste grupo, eram estreitados os laços criados na comunidade: "eu acho que no Yahoo [...] existem mais / os desabafos etc. / talvez por ser e-mail [...] um é mais a extensão do outro". É interessante notar que, para Estela, apesar de serem ambientes distintos e independentes, Orkut e e-mail eram vistos como complementares. Passou a haver, então, uma divisão espontânea entre os assuntos tratados na comunidade - onde havia uma grande quantidade de pessoas - e no grupo de troca de e-mails, mais restrito, apenas àquelas que haviam se tornado amigas. 
Divisão análoga era feita por Paulinho, membro da comunidade do site "Lance! Activo", porém através do MSN. Ele explicou: "Os amigos do [Lance!] activo eu incluo neste MSN... [Esse MSN é só pra falar de futebol?] Não. Para falar com as pessoas que conheci no activo. Mas não é exclusivamente para falar de futebol'".

Além de usar o ambiente do jogo Ragnarok para falar com os amigos que lá havia conhecido, Eduardo também recorria ao MSN e Orkut. Nestes últimos ambientes, surgiam outros temas além do próprio jogo: "usamos forum, msn, orkut e os assuntos estão voltados para algum jogo [...] só no fim do dia.. eh $q$ falamos de futebol, cinema, mulher, etc".

Os blogs eram outro ambiente no qual os pesquisados davam continuidade à relação que haviam iniciado nas comunidades. Noiva Lalá descreveu como isso acontecia, mencionando que, além de blogs, as noivas criavam também "site de casamento", nos quais aprofundavam as amizades geradas na comunidade: "muitas noivas fazem seu próprio blog pra compartilhar os preparativos de seus casamentos com outras noivas / e tem tb [também] o site de casamento q é bem bacana / [...] é mais pra contar e acompanhar a historia uma da outra".

\section{Discussão: Estreitando Laços Online, Impasses e Soluções}

Para interpretarmos nossos resultados, faz-se necessário que usemos um contraponto que nos permita o distanciamento necessário para que visualizemos os processos que lhes são subjacentes. Tal contraponto é facilmente localizável nas mudanças ocorridas nas relações interpessoais durante a passagem do sistema comunitário feudal para o sistema capitalista, descrita no início deste artigo. Vejamos.

Como afirmamos anteriormente, essas relações mudaram radicalmente com o surgimento dos grandes centros urbano-industriais no final do século XIX e início do século XX. Enquanto nas comunidades do período feudal que antecedeu a Revolução Industrial, homens, mulheres e crianças viviam entre pessoas com quem tinham vínculos fortes - de sangue, de vizinhança e/ou de crenças (ver Nicolaci-da-Costa, 2002) - os habitantes das metrópoles passaram a viver majoritariamente entre estranhos. Enquanto a convivência com os membros de uma comunidade feudal permitia o compartilhamento de praticamente tudo, a vida entre desconhecidos tornou necessária uma atitude radicalmente diferente, que não escapou à observação do sociólogo Georg Simmel (1910/1949).
Este percebeu que a vida nesses primeiros grandes centros urbano-industriais - ou metrópoles - desencadeou naqueles que neles viviam, a emergência, espontânea e inconsciente, de uma forma de defesa até então desnecessária: a reserva. A reserva, que até hoje é por nós empregada, consistia em discriminar quais aspectos de suas vidas poderiam ser expostos para diferentes audiências, ou seja, para diferentes círculos de relacionamentos. A exposição de si próprio passou a depender da distância ou proximidade em relação aos membros dos diversos círculos sociais (colegas de trabalho, vizinhos desconhecidos, amigos distantes e próximos, familiares etc.) dos quais inevitavelmente o habitante de uma grande metrópole faz parte. Quanto mais distantes ou superficiais os relacionamentos, menos deve ser revelado visando à autoproteção. A reserva se tornou tão importante que passou a caracterizar o homem e a mulher metropolitanos.

Isto se passou há mais de um século, no que diz respeito aos relacionamentos de carne-e-osso na "vida real". É, no entanto, exatamente a partir da reserva que cremos poder interpretar as trajetórias e estratégias empregadas pelos participantes da nossa pesquisa quando começaram a frequentar as comunidades virtuais de sua escolha e, principalmente, quando nelas começaram a fazer amigos. Tentemos tornar isso claro.

Os discursos dos homens e mulheres por nós entrevistados revelaram um interessante - e semelhante - percurso desde a escolha das comunidades às quais eles pertenciam até o surgimento das amizades. Inicialmente, os pesquisados escolheram comunidades que atendiam aos seus desejos de ter informações sobre assuntos específicos ou mesmo de ter momentos de lazer. Seu ingresso nas comunidades foi, portanto, ditado por interesses pessoais e pontuais (circunscritos a determinados assuntos). Assim sendo, foram protagonistas do que Castells (2003) vê como "individualismo em rede" e Wellman (2001) como "comunidades personalizadas". Esse, contudo, foi somente o início da trajetória que desejamos discutir.

Nessas comunidades, nossos entrevistados obviamente passaram a se relacionar com estranhos e a reserva entrou em operação. Para sua surpresa, no entanto, desenvolveram afinidades com alguns desses estranhos. Em consequência disso, acabaram por desejar desabafar, compartilhar amizades e alegrias com estes desconhecidos. Quando isso acontecia, conversar apenas sobre o tema da comunidade não mais satisfazia seus desejos; queriam abordar outros assuntos, alguns dos quais bem mais íntimos. A partir de então o ambiente da comunidade passava a ser sentido como 
insuficiente para o adensamento da relação. Não bastava mais trocar mensagens nas comunidades do Orkut, do jogo Ragnarok ou do site Lance!Activo, por exemplo. Esses ambientes pareciam limitados demais porque eram demasiadamente públicos, não permitindo que abrissem mão da reserva radical que haviam adotado inicialmente. Como disse Nayara a respeito do Orkut "não da[va] pra falar diretamente / [ter uma] conversa instantanea...". Na visão de Ana Carolina, faltava um "chat pessoal" nas redes de relacionamento. Isso era o que essas e outros entrevistados conseguiam perceber, mas, se levarmos em consideração os diferentes círculos de amizade aos quais todos pertencemos, faltavam, na realidade, espaços diferenciados para diferentes tipos de relacionamento.

Para superar tal limitação, nossos entrevistados procuraram meios através dos quais pudessem complementar e dar continuidade às trocas de experiências, desabafos, confissões, etc. iniciados nas comunidades das quais faziam parte. Para isso, recorreram ao uso de outros ambientes da Web, tais como o MSN, o Skype, o Twitter, os blogs etc. dependendo do tipo de relacionamento que desejavam ter com seus novos amigos e do quanto de reserva estavam dispostos a abdicar.

E esse raciocínio se aplica não somente aos ambientes projetados para albergar comunidades. Aplica-se também às redes sociais como o Orkut e o Facebook. Nestas, a necessidade que os usuários tiveram de abrir mão de diferentes graus de reserva para o estreitamento de seus diferentes tipos de relacionamento (levando à utilização de recursos da Web externos a essas redes) deve ter sido muito frequente. A prova disso é o que, desde que realizamos nossa pesquisa, vimos observando a introdução progressiva de espaços diferenciados dentro dos próprios ambientes dessas redes. Além disso, a recente proposta do Google+ já indica que essas reações foram registradas pelos desenvolvedores de ambientes de rede. Embora o Google+ ainda não esteja sendo muito utilizado, talvez porque a migração de toda uma rede de relacionamentos não é coisa trivial ou rápida (a migração do Orkut para o Facebook no Brasil é um bom exemplo), sua proposta inicial é a de que cada usuário aloque seus interlocutores a diferentes círculos de relacionamento que receberão mensagens destinadas somente a eles. Será este um sinal auspicioso de que a reserva que rege nossos relacionamentos no mundo "real" ganhará registro nos ambientes que se destinam a servir de plataforma para os nossos relacionamentos no mundo "virtual"?

\section{REFERÊNCIAS}

Castells, M. (2003). A galáxia da Internet: Reflexões sobre a internet, os negócios e a sociedade (M. L. X. A. Borges, Trans.). Rio de Janeiro: Zahar.

Corrêa, C. H. W. (2004). Comunidades virtuais gerando identidades na sociedade em rede. Revista Eletrônica Ciberlegenda, 13. Retirado de http://www.uff.br/mestcii/cyntia1.htm.

Di Luccio, F., \& Nicolaci-da-Costa, A. M. (2007). Escritores de blogs: Interagindo com os leitores ou apenas ouvindo ecos? Psicologia: Ciência e Profissão, 27, 664-679.

Di Luccio, F. (2010). Do iluminismo à web semântica: Reflexões sobre a comunicação com base em uma única língua (Tese de doutorado). Pontifícia Universidade Católica do Rio de Janeiro.

Durkheim, E. (1897). O suicídio: Um estudo sociológico (N. C. Caixeiro, Trans.). Rio de Janeiro: Zahar. (Trabalho original publicado em 1982)

Lemos, A. (2002). Cibercultura, tecnologia e vida social na cultura contemporânea. Porto Alegre: Sulina.

Maffesoli, M. (2006). O tempo das tribos: O declínio do individualismo nas sociedades de massa (M. L. Menezes, Trans.). Rio de Janeiro: Forense Universitária.

Marcelo, A. S. B. (2004). Novos media: Inauguração de novas formas de sociabilidade. In A. Fidalgo \& P. Serra (Eds.), Actas do III SOPCOM, VI LUSOCOM e II Ibérico (pp. 275). Lisboa: Associação Portuguesa de Ciências da Comunicação. Retirado de http://www.bocc.ubi.pt/pag/marcelo-ana-sofia-andre-ben tes-novos-media-inauguracao-novas-formas-solidariedade.pdf

Nicolaci-da-Costa, A. M. . (1997). Comunidade: Teorias e modelos. Psicologia: Pós-Graduação e Pesquisa, 8, 101-108.

Nicolaci-da-Costa, A. M. (2002). Revoluções tecnológicas e transformações subjetivas. Psicologia: Teoria e Pesquisa, 18, 193202.

Nicolaci-da-Costa, A. M. (2006). Internet: Uma nova plataforma de vida. In A. M. Nicolaci-da-Costa (Ed.), Cabeças digitais: $O$ cotidiano na era da informação (pp. 19-39). Rio de Janeiro/São Paulo: Editora PUC-Rio/Edições Loyola.

Nicolaci-da-Costa, A. M. (2007). O campo da pesquisa qualitativa e o método de explicitação do discurso subjacente (MEDS). Psicologia: Reflexão \& Crítica, 20, 65-73.

Nicolaci-da-Costa, A. M., Romão-Dias, D. \& Di Luccio, F. (2009). O uso de entrevistas on-line no método de explicitação do discurso subjacente (MEDS). Psicologia: Reflexão \& Crítica, 22, 36-46.

Nisbet, R. (1966). The sociological tradition. New York: Basic Books.

Nisbet, R. (1973). Comunidade (R. P. Neto, Trans.). In M. M. Foracchi e J. S. Martins (Eds.) Sociologia e sociedade: Leituras de introdução à sociologia (pp. 255-261). Rio de Janeiro: LTC.

Rheingold, H. (1993). The virtual community: Homesteading on the electronic frontier. Retirado de http://www.rheingold. $\mathrm{com} / \mathrm{vc} / \mathrm{book} /$

Simmel, G. (1949). Sociology of sociability. American Journal of Sociology, 55, 254-261. (Trabalho original publicado em 1910) 
Tönnies, F. (1887). Communauté et société. Paris: Ratz-C. E. P. L. (Trabalho original publicado em 1978)

Trotter, W. (1953). Instincts of the herd in peace and war. Oxford: Oxford University Press (Trabalho original publicado em 1919)

Wellman, B., \& Gulia, M. (1997). Net surfers don't ride alone: Virtual communities as communities. Retirado de http://citeseerx.ist.psu.edu/viewdoc/summary?doi=10.1.1.28.4 435\&rank=1
Wellman, B. (2001). Little boxes, glocalization and networked individualism. Retirado de http://homes.chass.utoronto.ca/ wellman/publications/littleboxes/littlebox.PDF

Recebido: 13/10/2011

Última revisão: 01/06/2012

Aceito: 09/08/2012 